\title{
Variability in kelp forest structure along a latitudinal gradient in ocean temperature
}

Dan A. Smale $\mathrm{e}^{1,2}$ and Pippa J. Moore ${ }^{3,4}$

${ }^{1}$ Marine Biological Association of the United Kingdom, The Laboratory, Citadel Hill, Plymouth PL1 2PB, UK

${ }^{2}$ School and Plant Biology and Oceans Institute, University of Western Australia, Crawley WA 6009, Western Australia, Australia

${ }^{3}$ Institute of Biological, Environmental and Rural Sciences, Aberystwyth University, Aberystwyth, SY23 3DA, UK.

${ }^{4}$ Centre for Marine Ecosystems Research, School of Natural Sciences, Edith Cowan University, Joondalup 6027, Western Australia, Australia

*Correspondence: Email: dansma@mba.ac.uk Fax: +44(0)1752633102; Phone: +44(0)1752633273 
ABSTRACT: Subtidal forests comprised of kelps and other canopy-forming macroalgae represent critically important marine habitats. Kelp forests exhibit high rates of primary productivity, magnified secondary productivity, support high levels of biodiversity and provide various ecosystem services. Compared with many other regions, kelp forests around the UK have been largely understudied despite their recognised importance and the possible impacts of environmental change factors. We conducted surveys at 12 kelp-dominated open-coast sites within four regions in the UK, spanning $\sim 9^{\circ}$ in latitude and $\sim 3^{\circ} \mathrm{C}$ in mean sea temperature. We used a combination of quadrat-scale abundance and percent cover data as well as transect-scale canopy cover estimates to quantify ecological structure at multiple spatial scales. Kelp forest structure varied significantly between sites (nested within region) and also between regions. Regional-scale differences were principally driven by a higher abundance/cover of Alaria esculenta at the colder northern regions (i.e. north and west Scotland), and the presence of the Lusitanian kelp Laminaria ochroleuca at some sites in the southernmost region (i.e. southwest England) but nowhere else. The kelp Laminaria hyperborea dominated all sites and varied significantly between sites but not regions. All assemblage-level and population-level response variables were highly variable between sites within regions, suggesting that environmental factors varying at corresponding spatial scales (e.g. wave exposure, turbidity, sedimentation) are important drivers of pattern. The detection of regional-scale variability suggests that predicted changes in ocean climate, particularly increased sea temperature, may lead to changes in kelp forest structure in the future, with poleward range contractions (for A. esculenta) and expansions (for L. ochroleuca) likely. However, as the distribution-abundance patterns of the assemblage dominant L. hyperborea did not vary predictably with ocean temperature at this spatial scale, the fundamental structure of these habitats may be more influenced by localised factors, at least in the short-term. The relative importance of multiple, concurrent environmental change factors in structuring UK kelp forests remains largely unknown. 
Keywords: Canopy-forming seaweeds; Laminariales; Macroalgal beds; Northeast Atlantic; Subtidal ecology; Temperate reefs.

\section{Introduction}

Kelp species (order Laminariales) dominate shallow rocky habitats in temperate and subpolar regions around the world (Steneck et al., 2002; Teagle et al., in press). Kelps function as foundation species by supporting high levels of primary productivity (Mann, 2000; Steneck et al., 2002) and promote and maintain diversity by providing food and habitat for a wealth of associated flora and fauna (Christie et al., 2003; Norderhaug et al., 2005; Teagle et al., in press). While some kelp derived material is consumed directly and transferred to higher trophic levels in situ (Norderhaug and Christie, 2009; Sjøtun et al., 2006), most is exported as kelp detritus which may be processed through the microbial loop, exported to adjacent habitats or consumed by a wide range of detritivores (Krumhansl and Scheibling, 2012). Kelps therefore play an important role in the capture and export of energy in coastal marine food webs (Dayton, 1985; Krumhansl and Scheibling, 2012). Kelps also provide a suite of other ecosystem services including biogenic storm protection, nutrient cycling, natural resources and nursery grounds and habitat for commercially important fish, mollusc and crustacean species (Beaumont et al., 2008; Bertocci et al., 2015; Steneck et al., 2002).

The structure and extent of kelp forest habitat is influenced by a variety of physical variables, including temperature (Tuya et al., 2012; Wernberg et al., 2016), light availability (Desmond et al., 2015; Lüning, 1979), nutrient levels (Dayton et al., 1999; Kain, 1989) and wave disturbance (Dayton and Tegner, 1984; Filbee-Dexter and Scheibling, 2012). Ecological processes such as overgrazing (Hart and Scheibling, 1988; Leinaas and Christie, 1996), competition (Arkema et al., 2009; Hawkins and Harkin, 1985) and facilitation (Arkema et al., 2009; Bennett and Wernberg, 2014) can also affect kelp forest structure and functioning. In 
addition, kelp forest ecosystems are currently threatened by a range of anthropogenic stressors (Mineur et al., 2015; Smale et al., 2013), including overfishing (Ling et al., 2009) increased temperature (Filbee-Dexter et al., 2016; Wernberg et al., 2016) and storminess (Byrnes et al., 2011; Smale and Vance, 2015), the spread of invasive species (Arnold et al., 2016; Saunders and Metaxas, 2008) and elevated nutrient and sediment inputs (Gorgula and Connell, 2004; Moy and Christie, 2012). As such, a range of concurrent, interacting processes operate at multiple spatial and temporal scales to exert control on kelp-dominated communities and ecosystems (Wernberg et al., 2011a).

As kelps and other brown canopy-forming macroalgae (i.e. fucoids) are generally cold-water adapted species, their geographical distributions, particularly the equatorial range edge, are strongly controlled by temperature (Lüning, 1984), although other factors such as light and nutrient levels are important in determining species distributions (Desmond et al., 2015; Gorman et al., 2013; Smale et al., 2016). The thermal ranges and optima of macroalgae differ between populations and species (Müller et al., 2009; Pang et al., 2007) and, as such, the structure and extent of kelp forests and macroalgal beds has been shown to change along natural gradients of temperature. For example, recent observational studies in Western Australia (Smale et al., 2010; Wernberg et al., 2011b) and Portugal (Tuya et al., 2012) have shown that the structure of macroalgae-dominated communities shift predictably with changes in temperature along latitudinal gradients. Within the context of climate change, increased sea temperatures have been linked to loss of marginal populations, range contractions and significant reductions in kelp forest extent (Raybaud et al., 2013; Tuya et al., 2012; Voerman et al., 2013; Wernberg et al., 2016). On the other hand, oceanic warming has also been linked with range expansions at the poleward edge for some warmer water species, such as Laminaria ochroleuca (Smale et al., 2015). Interestingly, in temperate regions that have undergone ocean cooling in recent decades, such as South Africa, cold water kelp species have extended their 
ranges, again highlighting the important role of ocean temperature in setting geographical distributions (Bolton et al., 2012). It is evident that recent changes in ocean climate have influenced the structure and extent of kelp forests in many regions, and further changes are predicted to occur (Brodie et al., 2014; Müller et al., 2009).

In the UK, suitable rocky reef habitat for kelp populations is found along much of the extensive and complex coastline, particularly along the wave-exposed south, west and north coasts (Yesson et al., 2015). Kelps are found on rocky reefs and artificial hard structures from the low intertidal $(<1 \mathrm{~m}$ above chart datum) to depths in excess of $40 \mathrm{~m}$ (e.g. Alaria esculenta off Rockall, Scotland). Eight kelp and pseudo-kelp species co-exist in UK waters (Smale et al., 2013), of which five are long-lived perennial species (Laminaria hyperborea, L. digitata, L. ochroleuca, Saccharina latissima, Alaria esculenta) and three are annual or pseudo-annual (Saccorhiza polyschides, Chorda filum, Undaria pinnatifida). The dominant canopy-former on most moderately-exposed to exposed sublittoral reefs is L. hyperborea, which is a stipitate canopy-forming kelp species with a rigid stipe (1-3m long) that holds the fronds above the substratum.

Technological advances in scuba diving in the 1960s and 1970s facilitated step-wise progress in our understanding of the distribution and ecology of kelp forests in the UK, particularly through an estimable body of work conducted by Joanna Kain on the ecology of Laminaria (see Kain, 1979, for an overview) and P.G. Moore's work on faunal assemblages within kelp holdfasts (Moore, 1971, 1973). From the 1980s onwards, however, changes in attitudes and regulations concerning scientific scuba diving, coupled with shifts in research priorities and relatively little commercial interest in kelps, have led to a dearth of primary research on kelp forests in UK waters (Smale et al., 2013). Sublittoral kelp beds persist along >12,000 miles of UK coastline yet the volume of directed research in recent years pales in significance when 
compared with kelp studies conducted in other research intensive nations (Smale et al. 2013). This lack of targeted research has led to significant knowledge gaps that currently hinder management and conservation of these habitats, such as a scarcity of robust baseline data against which to detect ecological change driven by contemporary stressors. Here, we conducted large-scale kelp forest surveys across $9^{\circ}$ of latitude in order to generate a robust baseline of ecological pattern at relevant spatial scales. The study regions encompassed a gradient in sea temperature of $\sim 3^{\circ} \mathrm{C}$ and survey sites ranged from moderately to fully waveexposed. As such, we predicted that kelp forest structure would (1) vary at regional spatial scales due to changes in ocean climate (e.g. temperature) and (2) vary at smaller spatial scales (i.e. between sites) due to variability in localised factors (e.g. wave exposure, sedimentation, turbidity).

\section{Material and methods}

\subsection{Study area}

Surveys were conducted at 12 sites within four regions in the UK, which spanned $\sim 9^{\circ}$ in latitude $\left(\sim 50^{\circ} \mathrm{N}\right.$ to $\left.\sim 59^{\circ} \mathrm{N}\right)$ and were situated on the exposed western coastline of mainland UK (Fig. 1) where kelp forest habitat is abundant (Smale et al., 2013; Yesson et al., 2015). Adjacent regions were between $\sim 180$ and $500 \mathrm{~km}$ apart (Fig. 1). Within each region candidate study sites were selected based on the following criteria: (i) sites should support extensive subtidal rocky reef habitat at $\sim 3-5 \mathrm{~m}$ depth (below chart datum); (ii) sites should be representative of the wider region (in terms of coastal geomorphology) and not obviously influenced by localised anthropogenic activities (e.g. sewage outfalls, fish farms); and (iii) sites should be 'open coast' and moderately to fully exposed to wave action to ensure a dominance of L. hyperborea (rather than Saccharina latissima which dominates sheltered coastlines typical of Scottish sea lochs, 
for example). Data on light intensity and nutrient levels from most sites are presented in Smale et al. (2016) and were not suggestive of any point-source anthropogenic impacts. Three sites were randomly selected from a larger pool; sites were situated between $\sim 1$ and $\sim 13 \mathrm{~km}$ apart within each region (Fig. 2). At one site within each region, sea temperature within the kelp forest was monitored for 1 annual cycle (July 2014-July 2015) by deploying a 'HOBO Tidbit' logger on the reef's surface, which measured temperature every 30 minutes. Information on environmental factors of known importance to kelp population structure were collated for each survey site. Satellite-derived SSTs were obtained (rom the NASA Giovanni Data Portal, using 9-km resolution data from the Pathfinder AVHRR satellite) and used to generate monthly means for February and August (i.e. monthly minima and maxima), averaged from 2000-2006. Land masks were used to remove any influence of coastal pixels and site values were averaged across all pixels within a $30 \mathrm{~km}$ radius. Remotely-sensed estimates of chlorophyll $a$ concentrations (collected by the MODIS Aqua satellite at an estimated 9-km resolution) were extracted and averaged over the period 2002-2012 as a proxy for water turbidity (see Burrows, 2012 for similar approach). Wave exposure was quantified using fetch values presented in Burrows et al. (2008) and Burrows (2012). Finally, average summer day length (mean value for all days in June and July) was used as a proxy for maximum photoperiod for each region. Grazing by sea urchins is not considered to be a major driver of kelp forest structure within the study region (Smale et al., 2013) and densities of sea urchins (predominantly Echinus esculentus) are low at these sites (Smale et al., 2016). In general, benthic communities within these kelp forest sites are characterised by a high coverage of understorey algae (predominantly Rhodophytes), patchy cover of sessile invertebrates (e.g. sponges, ascidians, bryozoans) and extensive and dense kelp canopies.

\subsection{Kelp forest surveys}


At each study site scuba divers assessed the structure of the kelp forest in 3 ways: (i) quadratscale abundance counts; (ii) quadrat-scale percent cover estimates; and (iii) transect-scale canopy cover estimates. The 3 different techniques were employed to ensure that spatial variability was captured at both fine (i.e. quadrats) and habitat (i.e. transects) scales and because some species (e.g. Alaria esculenta) can form dense aggregations with relatively low spatial cover whereas others (e.g. Saccorhiza polyschides) may have relatively low abundances but high spatial coverage and therefore have the potential to influence proximal assemblages. Quadrat-scale surveys were conducted by haphazardly placing eight replicate $1 \mathrm{~m}^{2}$ quadrats (placed $>3 \mathrm{~m}$ apart) within kelp forest habitat. Within each quadrat, the abundance of all kelp species was quantified by counting the number of holdfasts within the sampling area (small, undivided Laminaria sporelings less than $10 \mathrm{~cm}$ in length were not enumerated because of uncertainties in identification and considerable spatial patchiness). Additionally, the total spatial coverage of each species was recorded (estimates of total percent cover often exceeded $100 \%$ due to the 3-dimensional multi-layered structure of the habitat).

Wider habitat-scale assessments of kelp forest structure were performed by conducting $25-\mathrm{m}$ long belt transects (4 replicates per site), which were randomly orientated but stratified for rocky substrata. A tape measure was laid out over the canopy and the coverage (\%) and composition (identity of kelp species) of the canopy was quantified within multiple $5 \mathrm{~m}$ length and $2 \mathrm{~m}$ width segments, giving 5 subsamples (segments) per transect and a total transect area of $50 \mathrm{~m}^{2}$. The percent cover of each kelp species was estimated, as was the area of rocky reef without canopy. All surveys were conducted in early summer (May-June) 2016. All sites comprised extensive, largely continuous kelp canopies and all survey data were collected from within the kelp forest (i.e. at least $5 \mathrm{~m}$ from an obvious habitat boundary) on stable bedrock. The large brown macroalga Saccorhiza polyschides is taxonomically placed within the order 
Tilopteridales and not within the Laminariales, but we considered this species a 'kelp' given that it serves a similar canopy-forming function in many locations.

\subsection{Statistical analysis}

Spatial variability in multivariate kelp forest structure was examined with PERMANOVA (Anderson et al., 2008), using a 2-factor model comprising Region (fixed, 4 levels) and Site (random, 3 levels and nested within Region). Datasets arising from each sampling method (i.e. quadrat-scale abundance, quadrat-scale cover and transect-scale canopy cover) were analysed separately and all data were fourth-root transformed prior to analysis to downweight the importance of L. hyperborea, which was dominant at all sites. Permutations (4999 under a reduced model) were conducted on Bray-Curtis similarity matrices and significance was accepted at $\mathrm{P}<0.05$. Spatial patterns in multivariate habitat structure were visualised with metric MDS ordinations. As significant between-region variability in kelp forest was detected, a SIMPER analysis was performed on each dataset to determine which species were the principal contributors to the observed differences between regions. Moreover, the RELATE procedure was used to determine whether regional shifts in multivariate assemblage structure were correlated with changes in latitude. The RELATE test used a simple model matrix constructed from the latitude of each region, which was compared with a similarity matrix derived from (site-averaged) kelp assemblage data; Pearson's $\rho$ was used to quantify the strength of the correlation.

For each kelp species individually, variability between regions and sites (nested within regions) was examined with univariate permutational ANOVA. Similarity matrices based on Euclidean distances between untransformed abundance/cover data were constructed for each species and dataset, and analysis was performed using the same model described above. All statistical 
procedures were conducted with PRIMER 7 and the PERMANOVA+ add-on (Anderson et al., 2008; Clarke and Warwick, 2001).

\section{Results}

The study regions encompassed a gradient in ocean temperature of $\sim 2.9^{\circ} \mathrm{C}$, based on the insitu annual temperature record for July 2014-July 2015 (Fig. 2). Longer-term average temperatures for these regions, derived from remotely-sensed SSTs, also show that the wider study area spans a temperature gradient of $\sim 3^{\circ} \mathrm{C}$ (Smale et al. 2016). However, changes in temperature were not incremental between the regions, as the 2 northernmost and 2 southernmost regions exhibited similar climatologies (Fig. 2). For example, the maximum temperature observed during the annual cycle in northern Scotland and western Scotland was $14.1^{\circ} \mathrm{C}$ and $14.6^{\circ} \mathrm{C}$, respectively, whereas maximum temperatures in southwest Wales and southwest England were $17.9^{\circ} \mathrm{C}$ and $18.0^{\circ} \mathrm{C}$ (Fig. 2). Environmental data collated for each site indicated clear differences in summer temperatures and day-length between regions, as well as variability in wave fetch and reef type within regions (Table 1). Chlorophyll $a$ concentrations varied (to some extent) both between and within regions (Table 1).

The structure of kelp forest habitat, as determined by all three survey methods, varied significantly between regions and sites nested within region (Table 2). Metric MDS plots showed that, aside from considerable site-level variability, kelp forest structure generally shifted sequentially with latitude, as sites in the northernmost regions were distinct from those in the southern regions, although this was least pronounced for quadrat-scale abundance counts (Fig. 3). Regional-scale partitioning was particularly evident at the transect-scale, as kelp habitats within northern Scotland and western Scotland tended to be clustered together and disparate from those in southwest Wales and southwest England (Fig. 3). Metric MDS plots were also generated using data averaged across each site, to encapsulate small-scale variability 
and facilitate comparisons across regions (Fig. 4). Site-averaged ordinations indicated clear partitioning between the northern Scotland region and the other regions across all survey methods, whilst at the transect-scale both northern and western Scotland regions were distinct from the southernmost regions (Fig. 4). The RELATE test based on a simple model matrix constructed from latitude showed that shifts in assemblage structure were moderately but significantly correlated with changes in latitude for all 3 survey methods (quadrat abundance: Pearson's $\rho=0.43, \mathrm{P}=0.002$; quadrat cover: Pearson's $\rho=0.40, \mathrm{P}=0.001$; transect cover: Pearson's $\rho=0.40, \mathrm{P}=0.002$ ).

With regards to the kelp species contributing to the observed variability between regions, SIMPER analysis indicated that variation between kelp forest structure in northern Scotland and all other regions was primarily driven by Alaria esculenta (Fig. 5). Conversely, variability between kelp forests in southwest England and the other regions was primarily driven by the occurrence of Laminaria ochroleuca, which was the most important discriminator between southwest England and both southwest Wales and western Scotland, and the second most important contributor to the dissimilarity with northern Scotland (Fig. 5). These patterns were consistent between the 3 survey methods. However, the importance of the other species as discriminators between regions did vary between survey methods, as Laminaria hyperborea was an important contributor to the observed differences between regions when using quadratscale abundance counts, Saccharina latissima was important when quantifying by quadratscale percent cover and Saccorhiza polyschides was important when quantifying by transectscale canopy cover estimates (Fig. 5).

Univariate permutational ANOVAs (conducted separately for each species and each survey method) and plots of mean abundance/cover values showed marked differences between species in terms of spatial variability patterns. The assemblage dominant, Laminaria hyperborea, exhibited highly significant between-site (nested within region) variability (Table 
3) but did not vary significantly or consistently between regions, although the greatest values for both abundance and cover were recorded in northern Scotland (Fig. 6). These variability patterns were relatively consistent between survey methods (Table 3, Fig. 6). In contrast, $L$. ochroleuca was observed only in southwest England, and only at a single site with quadratscale surveys and at 2 sites with transect-scale surveys (Table 3, Fig. 6). As such, L. ochroleuca varied significantly between sites but not across regions (Table 3). Saccharina latissima was recorded within all regions but varied considerably between sites nested within region, a pattern that was consistent between the 3 survey methods (Fig. 6). Given high variability between sites, S. latissima did not differ significantly between regions (Table 3). Alaria esculenta showed significant variability between sites and between regions (Table 3). Abundance and cover (both quadrat and transect-scale) values were greatest at sites within northern Scotland (Fig. 6), while it was not recorded in the two southernmost regions (Fig. 6). At the quadrat-scale, the abundance and cover of Saccorhiza polyschides was highly variable and differences between regions and sites were non-significant (Table 3). Conversely, significant variability was recorded between sites and regions at the transect-scale; S. polyschides appeared to be generally more abundant and widespread in the southern regions but with considerable site-level variability (Fig. 6).

\section{Discussion}

Our large-scale surveys of kelp forests in the UK supported our first prediction to some extent, in that we observed regional-scale variability in kelp forest structure which was partially aligned to regional-scale changes in ocean temperature with latitude. At the assemblage level, the two main discriminatory species underpinning this pattern were Alaria esculenta and Laminaria ochroleuca. The northerly-distributed A. esculenta was a common component of kelp forests in northern and western Scotland, being observed in 5 out of 6 sites, but was not 
recorded in the two southernmost regions. A. esculenta is found around the UK but has a distinctly boreal distribution (Brodie et al., 2014) and is particularly sensitive to high temperatures; both the gametophyte and sporophyte life stages are compromised at temperatures $>17^{\circ} \mathrm{C}$ (Fredersdorf et al., 2009; tom Dieck, 1993). Population structure of $A$. esculenta in the British Isles is strongly influenced by sea temperature (Yesson et al., 2015) and recent ocean warming trends have been linked with declining abundances of $A$. esculenta in some regions (Simkanin et al., 2005). While it is still found in southwest England and Wales, these range-edge populations are fragmented and were not present at any of the study sites in the current survey. In contrast, A. esculenta is abundant and widespread in Scotland, where it can serve as the dominant canopy former under very wave exposed conditions (Norton and Milburn, 1972). The abundance and cover of A. esculenta was also highly variable between sites nested within regions, and in both northern and western Scotland it tended to be more abundant at the most wave exposed sites. A. esculenta is characteristic of highly wave-exposed shores in the northeast Atlantic (Burrows et al., 2008) and can become dominant under extremely wave-exposed conditions that exceed thresholds for Laminaria species (Dalby et al., 1978). As such, local-scale differences in wave exposure may have driven, at least in part, the pronounced site-level variability we observed here.

The converse regional-scale latitudinal pattern was recorded for Laminaria ochroleuca, which is a more southerly-distributed species of Lusitanian origin that extends from the southwest of the UK south into the warm waters off Morocco and into the Mediterranean (Hargrave et al., in press; Smale et al., 2013; Voerman et al., 2013). Recent evidence suggests that marginal populations of $L$. ochroleuca have proliferated at the leading range edge, in line with recent increases in sea temperature (Smale et al., 2015), and L. ochroleuca is now common and widespread along moderately wave exposed coasts in southwest England. L. ochroleuca was the second most abundant kelp at the most sheltered site in southwest England, and was also 
recorded in transects at another site in the region, but was not recorded elsewhere. Hence, it was a key discriminatory species in driving the observed dissimilarity between kelp forest structure in southwest England and the other regions, even though variability between sites far outweighed variability between regions. The marked degree of site-level variability we observed may have been related to differences in wave exposure between sites, as $L$. ochroleuca is more susceptible to wave-induced dislodgement and mortality than $L$. hyperborea (Smale and Vance, 2015) and is generally restricted to moderately (rather than fully) wave-exposed sites (John, 1969; Smale et al., 2015). However, other factors such as light availability and sedimentation rates are also known the influence the distribution of $L$. ochroleuca (Izquierdo et al., 2002; John, 1969), and may also be important here.

Overall, our study provided stronger support for our second prediction, that between-site variation would be an observable and important component of spatial variability in kelp forest structure. At the assemblage level, site-level variability was highly significant regardless of the survey method and at the population-level all kelp species exhibited significant site-level variability for at least one of the survey methods. The assemblage dominant, L. hyperborea, was the most abundant kelp species at all survey sites, regardless of the survey methodology. A recent study on L. hyperborea populations in these regions showed that standing biomass and carbon stock was greatest in the northernmost regions, whereas the density of canopyforming plants was strongly influenced by between-site variability in exposure to waves and tides (Smale et al., 2016). The current study further highlights the importance of wave exposure and local conditions, given that the abundance, percent cover and canopy cover of $L$. hyperborea exhibited highly significant variability between sites within regions. Extensive work on L. hyperborea populations in Norway has also demonstrated the importance of wave exposure in determining their density, morphology and distribution (Bekkby et al., 2009; Pedersen et al., 2012), and increased exposure to waves may facilitate L. hyperborea 
populations by limited self-shading, reducing epiphyte loads and increasing nutrient exchange (Pedersen et al., 2012). We suggest that between-site variability in exposure to wave and tidal action (Smale et al., 2016), and concurrent variability in sedimentation rates, was important in driving site-level differences in the abundance and cover of L. hyperborea.

The other kelp species surveyed, Saccharina latissima and Saccorhiza polyschides, were highly variable at small spatial scales (i.e. between sites and replicate quadrats/transects). Both species are competitively inferior to L. hyperborea on wave-exposed open coastlines (Hawkins and Harkin, 1985) but both are opportunistic early-colonisers of free space, and can occupy marginal habitats (e.g. semi-stable substrata, sediment-inundated bedrock). As such, these species were patchily distributed, often forming aggregations on the edge of reefs, in gullies or within sporadic gaps in the L. hyperborea canopy.

We employed three different methodologies for quantifying kelp forest structure, namely quadrat-scale abundance and percent cover, and transect-scale canopy cover. The three approaches yielded similar, but not identical, patterns at the assemblage level but differed considerably at the population level for some species. Essentially, the high resolution quadratscale abundance data provided robust estimates for the assemblage dominant, Laminaria hyperborea, which was widespread but exhibited a four-fold difference in abundance across the sites. Given the high densities of L. hyperborea compared with other kelps, assemblagelevel patterns in structure were strongly influenced by L. hyperborea when using the quadratscale abundance approach. On the other hand, the quadrat-scale percent cover approach elevated the importance of $S$. latissima and A. esculenta, as percent cover is more sensitive to species that have relatively lower densities but higher spatial coverage due to their size and morphologies (both species form elongated prostrate sporophytes). As such, variability in assemblage-level patterns were more influenced by these species when adopting the quadratscale percent cover approach. Finally, the transect-scale canopy cover method was more 
suitable for sampling patchily-distributed or rare species (i.e. Saccorhiza polyschides and $L$. ochroleuca), which were recorded in transects but not in quadrats at some sites. However, this approach had relatively limited ability to detect change in the abundance of the commonest species between sites and regions. Previous work on macroalgae-dominated communities has shown that different survey techniques may yield different patterns due to variability in detectability between taxa (Edwards and Tinker, 2009; Leonard and Clark, 1993). Here, the three methodologies returned comparable but varying data on the structure of UK kelp forests, most likely due to differences in abundance distribution patterns and morphologies between species. We suggest, therefore, that future survey and monitoring efforts should adopt a multifaceted approach in order to detect both subtle changes in the abundances of the commonest species as well as wider scale shifts in the occurrence of rare or clustered species.

In conclusion, despite pronounced site-level variability, we recorded significant variability in kelp forest structure at regional spatial scales, with detectable structural shifts occurring over a latitudinal temperature gradient of approximately $3{ }^{\circ} \mathrm{C}$ in UK coastal waters. While the abundance of the assemblage dominant, L. hyperborea, was relatively consistent across the study regions, some co-existing species did show marked variability along the temperature gradient. Given that sea temperatures around the UK have significantly increased in recent decades (Belkin, 2009) and are predicted to rise throughout the $21^{\text {st }}$ century (Philippart et al., 2011), it is likely that species found at their range edges will undergo distributional shifts as a result. As L. ochroleuca and A. esculenta are found towards their leading and trailing range edges, respectively, in UK waters they may serve as useful indicators of ocean climate change. A similar philosophy has been developed for kelp forests in Western Australia (Smale et al., 2010; Smale and Wernberg, 2013), where macroalgal species with clear latitudinal abundance patterns and demonstrable sensitivities to temperature change have been proposed as ecological indicators. 
More generally, by using a space-for-time substitution approach it is possible to predict the likely effects of gradual seawater warming on kelp forest structure and functioning. As mean sea temperatures in the wider study region are predicted to increase by $1.5-5^{\circ} \mathrm{C}$ by the end of the century (Philippart et al., 2011), kelp forest structure in our northernmost regions may become more similar to that currently observed in the southernmost regions (assuming other key drivers remain relatively constant). Specifically, we could expect to observe a proliferation of L. ochroleuca and a decline and range contraction of A. esculenta. Clearly, temperature is a key driver of these ecosystems but more localised factors are also important and may interact with warming in complex ways (Smale and Vance, 2015; Wernberg et al., 2011a). Improved monitoring and process-orientated research is needed to better our understanding and predictions of the effects of global environmental change on these critical habitats.

\section{Acknowledgments}

D.A.S. is supported by an Independent Research Fellowship awarded by the Natural Environment Research Council of the UK (NE/K008439/1). Fieldwork was supported by the NERC National Facility for Scientific Diving (NFSD) through a grant awarded to D.A.S. (NFSD/14/01). P.J.M. is supported by a Marie Curie Career Integration Grant (PCIG10-GA2011-303685). We thank all participants of 'Team Kelp (UK)' field expeditions (2014-2016) and Jo Porter, Peter Rendle, Martin Sayer, Mike Burrows, Sula Divers, In Deep and NFSD dive teams for technical and logistical support. Jack Sewell provided artwork for Fig. 5.

\section{References}

Anderson, M.J., Gorley, R.N., Clarke, K.R., 2008. Permanova+ for primer: guide to software and statistical methods. PRIMER-E, Plymouth, UK. 
Arkema, K.K., Reed, D.C., Schroeter, S.C., 2009. Direct and indirect effects of giant kelp determine benthic community structure and dynamics. Ecology 90, 3126-3137.

Arnold, M., Teagle, H., Brown, M.P., Smale, D.A., 2016. The structure of biogenic habitat and epibiotic assemblages associated with the global invasive kelp Undaria pinnatifida in comparison to native macroalgae. Biol. Invasions 18, 661-676.

Beaumont, N.J., Austen, M.C., Mangi, S.C., Townsend, M., 2008. Economic valuation for the conservation of marine biodiversity. Mar. Poll. Bull. 56, 386-396.

Bekkby, T., Rinde, E., Erikstad, L., Bakkestuen, V., 2009. Spatial predictive distribution modelling of the kelp species Laminaria hyperborea. ICES J. Mar. Sci. 66, 2106-2115.

Belkin, I.M., 2009. Rapid warming of large marine ecosystems. Prog. Oceanogr. 81, 207-213.

Bennett, S., Wernberg, T., 2014. Canopy facilitates seaweed recruitment on subtidal temperate reefs. J. Ecol. 102, 1462-1470.

Bertocci, I., Araújo, R., Oliveira, P., Sousa-Pinto, I., 2015. Potential effects of kelp species on local fisheries. J. Appl. Ecol. 52, 1216-1226.

Bolton, J.J., Anderson, R.J., Smit, A.J., Rothman, M.D., 2012. South African kelp moving eastwards: the discovery of Ecklonia maxima (Osbeck) Papenfuss at De Hoop Nature Reserve on the south coast of South Africa. Afr. J. Mar. Sci. 34, 147-151.

Brodie, J., Williamson, C.J., Smale, D.A., Kamenos, N.A., Mieszkowska, N., Santos, R., Cunliffe, M., Steinke, M., Yesson, C., Anderson, K.M., Asnaghi, V., Brownlee, C., Burdett, H.L., Burrows, M.T., Collins, S., Donohue, P.J.C., Harvey, B., Foggo, A., Noisette, F., Nunes, J., Ragazzola, F., Raven, J.A., Schmidt, D.N., Suggett, D., Teichberg, M., Hall-Spencer, J.M., 2014. The future of the northeast Atlantic benthic flora in a high CO2 world. Ecol. Evol. 4, 2787-2798. 
Burrows, M.T., 2012. Influences of wave fetch, tidal flow and ocean colour on subtidal rocky communities. Mar. Ecol. Prog. Ser. 445, 193-207.

Burrows, M.T., Harvey, R., Robb, L., 2008. Wave exposure indices from digital coastlines and the prediction of rocky shore community structure. Mar. Ecol. Prog. Ser. 353, 1-12.

Byrnes, J.E., Reed, D.C., Cardinale, B.J., Cavanaugh, K.C., Holbrook, S.J., Schmitt, R.J., 2011. Climate-driven increases in storm frequency simplify kelp forest food webs. Glob. Change Biol. 17, 2513-2524.

Christie, H., Jorgensen, N.M., Norderhaug, K.M., Waage-Nielsen, E., 2003. Species distribution and habitat exploitation of fauna associated with kelp (Laminaria hyperborea) along the Norwegian coast. J. Mar. Biol. Assoc. UK 83, 687-699.

Clarke, K.R., Warwick, R.M., 2001. Change in marine communities: an approach to statistical analysis and interpretation, 2nd ed. PRIMER-E Ltd., Plymouth, UK.

Dalby, D.H., Cowell, E.B., Syratt, W.J., Crothers, J.H., 1978. An exposure scale for marine shores in western Norway. J. Mar. Biol. Assoc. UK 58, 975-996.

Dayton, P.K., 1985. Ecology of kelp communities. Ann. Rev. Ecol. Syst. 16, 215-245.

Dayton, P.K., Tegner, M.J., 1984. Catastrophic storms, El Niño, and patch stability in a southern California kelp community. Science 224, 283-285.

Dayton, P.K., Tegner, M.J., Edwards, P.B., Riser, K.L., 1999. Temporal and spatial scales of kelp demography: the role of oceanographic climate. Ecol. Monogr. 69, 219-250.

Desmond, M.J., Pritchard, D.W., Hepburn, C.D., 2015. Light limitation within southern New Zealand kelp forest communities. PLoS ONE 10, e0123676.

Edwards, M.S., Tinker, M.T., 2009. Monitoring benthic aIgal communides: a comparison of targeted and coefficient sampling methods. Algae 24, 111-120. 
Filbee-Dexter, K., Feehan, C.J., Scheibling, R.E., 2016. Large-scale degradation of a kelp ecosystem in an ocean warming hotspot. Mar. Ecol. Prog. Ser. 543, 141-152.

Filbee-Dexter, K., Scheibling, R.E., 2012. Hurricane-mediated defoliation of kelp beds and pulsed delivery of kelp detritus to offshore sedimentary habitats. Mar. Ecol. Prog. Ser. 455, 51-64.

Fredersdorf, J., Müller, R., Becker, S., Wiencke, C., Bischof, K., 2009. Interactive effects of radiation, temperature and salinity on different life history stages of the Arctic kelp Alaria esculenta (Phaeophyceae). Oecologia 160, 483-492.

Gorgula, S., Connell, S., 2004. Expansive covers of turf-forming algae on human-dominated coast: the relative effects of increasing nutrient and sediment loads. Mar. Biol. 145, 613-619.

Gorman, D., Bajjouk, T., Populus, J., Vasquez, M., Ehrhold, A., 2013. Modeling kelp forest distribution and biomass along temperate rocky coastlines. Mar. Biol. 160, 309-325.

Hargrave, M., Foggo, A., Pessarrodona, A., Smale, D.A., in press. Replacement at the range edge: the effects of warming on the ecophysiology of two co-existing kelp species in the northeast Atlantic. Oecologia.

Hart, M.W., Scheibling, R.E., 1988. Heat waves, baby booms, and the destruction of kelp beds by sea urchins. Mar. Biol. 99, 167-176.

Hawkins, S.J., Harkin, E., 1985. Preliminary canopy removal experiments in algal dominated communities low on the shore and in the shallow subtidal on the Isle of Man. Bot. Mar. 28, 223-230. Izquierdo, J., Pérez-Ruzafa, I., Gallardo, T., 2002. Effect of temperature and photon fluence rate on gametophytes and young sporophytes of Laminaria ochroleuca Pylaie. Helgoland Mar. Res. 55, 285292.

John, D.M., 1969. An ecological study on Laminaria ochroleuca. J. Mar. Biol. Assoc. UK 49, 175187. 
Kain, J.M., 1979. A view of the genus Laminaria. Oceanogr. Mar. Biol. Ann. Rev. 17, 101-161.

Kain, J.M., 1989. Seasons in the subtidal. Brit. Phycol. J. 24, 203-215.

Krumhansl, K., Scheibling, R.E., 2012. Production and fate of kelp detritus. Mar. Ecol. Prog. Ser. 467, 281-302.

Leinaas, H., Christie, H., 1996. Effects of removing sea urchins (Strongylocentrotus droebachiensis): Stability of the barren state and succession of kelp forest recovery in the east Atlantic. Oecologia 105, $524-536$.

Leonard, G.H., Clark, R.P., 1993. Point quadrat versus video transect estimates of the cover of benthic red algae. Mar. Ecol. Prog. Ser. 101, 203-208.

Ling, S.D., Johnson, C.R., Frusher, S.D., Ridgway, K.R., 2009. Overfishing reduces resilience of kelp beds to climate-driven catastrophic phase shift. Proc. Nat. Acad. Sci. USA 106, 22341-22345.

Lüning, K., 1979. Growth strategies of three Laminaria species (Phaeophyceae) inhabiting different depth zones in the sublittoral region of Helgoland (North Sea). Mar. Ecol. Prog. Ser. 1, 195-207.

Lüning, K., 1984. Temperature tolerance and biogeography of seaweeds: The marine algal flora of Helgoland (North Sea) as an example. Helgoländer Meeresun. 38, 305-317.

Mann, K.H., 2000. Ecology of coastal waters. Blackwell, Malden, Masaschusetts USA.

Mineur, F., Arenas, F., Assis, J., Davies, A.J., Engelen, A.H., Fernandes, F., Malta, E.-j., Thibaut, T., Van Nguyen, T., Vaz-Pinto, F., Vranken, S., Serrão, E.A., De Clerck, O., 2015. European seaweeds under pressure: Consequences for communities and ecosystem functioning. J. Sea Res. 98, 91-108.

Moore, P.G., 1971. The nematode fauna associated with holdfasts of kelp (Laminaria hyperborea) in northeast Britain. J. Mar. Biol. Assoc. UK 51, 589-604. 
Moore, P.G., 1973. The kelp fauna of northeast Britain. II. Multivariate classification: Turbidity as an ecological factor. J. Exp. Mar. Biol. Ecol. 13, 127-163.

Moy, F.E., Christie, H., 2012. Large-scale shift from sugar kelp (Saccharina latissima) to ephemeral algae along the south and west coast of Norway. Mar. Biol. Res. 8, 309-321.

Müller, R., Laepple, T., Bartsch, I., Wiencke, C., 2009. Impact of ocean warming on the distribution of seaweeds in polar and cold-temperate waters. Bot. Mar. 52, 617-638.

Norderhaug, K.M., Christie, H., Fosså, J.H., Fredriksen, S., 2005. Fish-macrofauna interactions in a kelp (Laminaria hyperborea) forest. J. Mar. Biol. Assoc. UK 85, 1279-1286.

Norderhaug, K.M., Christie, H.C., 2009. Sea urchin grazing and kelp re-vegetation in the NE Atlantic. Mar. Biol. Res. 5, 515-528.

Norton, T.A., Milburn, J.A., 1972. Direct observations on the sublittoral marine algae of Argyll, Scotland. Hydrobiologia 40, 55-68.

Pang, S.J., Jin, Z.H., Sun, J.Z., Gao, S.Q., 2007. Temperature tolerance of young sporophytes from two populations of Laminaria japonica revealed by chlorophyll fluorescence measurements and shortterm growth and survival performances in tank culture. Aquaculture 262, 493-503.

Pedersen, M.F., Nejrup, L.B., Fredriksen, S., Christie, H., Norderhaug, K.M., 2012. Effects of wave exposure on population structure, demography, biomass and productivity of the kelp Laminaria hyperborea. Mar. Ecol. Prog. Ser. 451, 45-60.

Philippart, C.J.M., Anadon, R., Danovaro, R., Dippner, J.W., Drinkwater, K.F., Hawkins, S.J., Oguz, T., O'Sullivan, G., Reid, P.C., 2011. Impacts of climate change on European marine ecosystems: Observations, expectations and indicators. J. Exp. Mar. Biol. Ecol. 400, 52-69.

Raybaud, V., Beaugrand, G., Goberville, E., Delebecq, G., Destombe, C., Valero, M., Davoult, D., Morin, P., Gevaert, F., 2013. Decline in kelp in west Europe and climate. PLoS ONE 8, e66044. 
Saunders, M., Metaxas, A., 2008. High recruitment of the introduced bryozoan Membranipora membranacea is associated with kelp bed defoliation in Nova Scotia, Canada. Mar. Ecol. Prog. Ser. $369,139-151$.

Simkanin, C., Power, A.M., Myers, A., McGrath, D., Southward, A., Mieszkowska, N., Leaper, R., O'Riordan, R., 2005. Using historical data to detect temporal changes in the abundances of intertidal species on Irish shores. J. Mar. Biol. Assoc. UK 85, 1329-1340.

Sjøtun, K., Christie, H., Helge Fosså, J., 2006. The combined effect of canopy shading and sea urchin grazing on recruitment in kelp forest (Laminaria hyperborea). Mar. Biol. Res. 2, 24-32.

Smale, D.A., Burrows, M.T., Evans, A.J., King, N., J., S.M.D., Yunnie, A.L.E., Moore, P.J., 2016. Linking environmental variables with regional-scale variability in ecological structure and standing stock of carbon within kelp forests in the United Kingdom. Mar. Ecol. Prog. Ser. 542, 79-95.

Smale, D.A., Burrows, M.T., Moore, P.J., O' Connor, N., Hawkins, S.J., 2013. Threats and knowledge gaps for ecosystem services provided by kelp forests: a northeast Atlantic perspective. Ecol. Evol. 3, 4016-4038.

Smale, D.A., Kendrick, G.A., Wernberg, T., 2010. Assemblage turnover and taxonomic sufficiency of subtidal macroalgae at multiple spatial scales. J. Exp. Mar. Biol. Ecol. 384, 76-86.

Smale, D.A., Vance, T., 2015. Climate-driven shifts in species distributions may exacerbate the impacts of storm disturbances on northeast Atlantic kelp forests. Mar. Freshwater Res. 67, 65-74.

Smale, D.A., Wernberg, T., 2013. Extreme climatic event drives range contraction of a habitatforming species. Proc. Roy. Soc. B Biol. Sci. 280, 20122829

Smale, D.A., Wernberg, T., Yunnie, A.L.E., Vance, T., 2015. The rise of Laminaria ochroleuca in the Western English Channel (UK) and preliminary comparisons with its competitor and assemblage dominant Laminaria hyperborea. Mar. Ecol. 36, 1033-1044. 
Steneck, R.S., Graham, M.H., Bourque, B.J., Corbett, D., Erlandson, J.M., Estes, J.A., Tegner, M.J., 2002. Kelp forest ecosystems: biodiversity, stability, resilience and future. Environ Conserv 29, 436459.

Teagle, H., Hawkins, S.J., Moore, P.J., Smale, D.A., in press. The role of kelp species as biogenic habitat formers in coastal marine ecosystems. J. Exp. Mar. Biol. Ecol. accepted 13/06/2016.

tom Dieck, I., 1993. Temperature tolerance and survival in darkness of kelp gametophytes (Laminariales, Phaeophyta): ecological and biogeographical implications Mar. Ecol. Prog. Ser. 100, 253-264.

Tuya, F., Cacabelos, E., Duarte, P., Jacinto, D., Castro, J.J., Silva, T., Bertocci, I., Franco, J.N., Arenas, F., Coca, J., Wernberg, T., 2012. Patterns of landscape and assemblage structure along a latitudinal gradient in ocean climate. Mar. Ecol. Prog. Ser. 466, 9-19.

Voerman, S.E., Llera, E., Rico, J.M., 2013. Climate driven changes in subtidal kelp forest communities in NW Spain. Mar. Environ. Res. 90, 119-127.

Wernberg, T., Bennett, S., Babcock, R.C., de Bettignies, T., Cure, K., Depczynski, M., Dufois, F., Fromont, J., Fulton, C.J., Hovey, R.K., Harvey, E.S., Holmes, T.H., Kendrick, G.A., Radford, B., Santana-Garcon, J., Saunders, B.J., Smale, D.A., Thomsen, M.S., Tuckett, C.A., Tuya, F., Vanderklift, M.A., Wilson, S.K., 2016. Climate driven regime shift of a temperate marine ecosystem. Science 353, 169-172.

Wernberg, T., Russell, B.D., Moore, P.J., Ling, S.D., Smale, D.A., Coleman, M., Steinberg, P.D., Kendrick, G.A., Connell, S.D., 2011a. Impacts of climate change in a global hotspot for temperate marine biodiversity and ocean warming. J. Exp. Mar. Biol. Ecol. 400, 7-16.

Wernberg, T., Thomsen, M.S., Tuya, F., Kendrick, G.A., 2011b. Biogenic habitat structure of seaweeds change along a latitudinal gradient in ocean temperature. J. Exp. Mar. Biol. Ecol. 400, 264271. 
Yesson, C., Bush, L.E., Davies, A.J., Maggs, C.A., Brodie, J., 2015. The distribution and environmental requirements of large brown seaweeds in the British Isles. J. Mar. Biol. Assoc. UK 95, 669-680. 
Table 1. Environmental characteristics for each survey site. Surveys were conducted at 12 subtidal rocky reef sites (depth shown in $\mathrm{m}$ below chart datum) within 4 distinct regions in the UK. All sites comprised extensive rocky reef habitat which was coarsely classified as either high relief (HR) or low relief (LR) and as either relatively flat platforms or deepening slopes. For each site, the average monthly temperature for February (i.e. monthly minima) and August (i.e. monthly maxima) was calculated from satellite-derived SST data (2000-2006). 'Log Chl $a$ mean' is the average annual concentration of chlorophyll for each site ( $\log 10 \mathrm{mg} \mathrm{m}^{-3}$ from MODIS Aqua satellite data, 2002 to 2012$)$. 'Log wave fetch' is a broad-scale metric of wave exposure, derived by summing fetch values calculated for 32 angular sectors surrounding each study site (see Burrows 2012). 'Mean summer day length' is the average day length (all days in June and July) at each site.

\section{Region/site}

N Scotland: A1

N Scotland: A2

N Scotland: A3

W Scotland: B1

W Scotland: B2

W Scotland: B3

SW Wales: C1

SW Wales: C2

SW Wales: C3

SW England: D1

SW England: D2

SW England: D3

$\begin{array}{ll}\text { Locality } & \begin{array}{l}\text { Dept } \\ (\mathbf{m})\end{array} \\ \text { Black Craig } & 5 \\ \text { Warbeth Bay } & 3 \\ \text { N Graemsay } & 4 \\ \text { Dubh Sgeir } & 5 \\ \text { W Kerrera } & 4 \\ \text { Ardmucknish Pt. } & 4 \\ \text { Stack Rock } & 5 \\ \text { Mill Haven } & 4 \\ \text { St. Brides } & 3 \\ \text { Hillsea Pt. } & 3 \\ \text { Stoke Pt. } & 4 \\ \text { NW Mewstone } & 4\end{array}$

$\begin{array}{ll}\begin{array}{l}\text { Reef } \\ \text { type }\end{array} & \begin{array}{l}\text { Feb mean } \\ \text { SST }\left({ }^{\circ} \mathbf{C}\right)\end{array} \\ \text { HR platform } & 7.5 \\ \text { LR platform } & 7.5 \\ \text { LR platform } & 7.4 \\ \text { LR slope } & 7.5 \\ \text { LR platform } & 7.5 \\ \text { LR slope } & 7.5 \\ \text { HR slope } & 8.4 \\ \text { HR platform } & 8.4 \\ \text { LR platform } & 8.4 \\ \text { HR platform } & 9.2 \\ \text { LR platform } & 9.1 \\ \text { LR platform } & 8.4\end{array}$

Aug mean
SST $\left({ }^{\circ} \mathbf{C}\right)$
13.5
13.5
13.4
13.8
13.8
13.7
16.4
16.4
16.5
17.0
17.0
16.4

$\begin{array}{lll}\begin{array}{l}\text { Log Chl } \boldsymbol{a} \\ \text { mean }\left(\mathbf{m g ~ m}^{-3}\right)\end{array} & \begin{array}{l}\text { Log wave fetch } \\ (\mathbf{k m})\end{array} & \begin{array}{l}\text { Mean summer } \\ \text { day length }(\mathbf{h r}: \mathbf{m i n})\end{array} \\ 0.21 & 4.1 & 18: 07 \\ 0.21 & 3.8 & 18: 07 \\ 0.26 & 3.5 & 18: 07 \\ 0.59 & 3.3 & 17: 19 \\ 0.65 & 3.1 & 17: 19 \\ 0.70 & 3.0 & 17: 19 \\ 0.43 & 3.7 & 16: 20 \\ 0.43 & 3.5 & 16: 20 \\ 0.43 & 3.4 & 16: 20 \\ 0.28 & 4.1 & 16: 08 \\ 0.28 & 3.9 & 16: 08 \\ 0.43 & 3.5 & 16: 08\end{array}$


Table 2. Results of PEMANOVA to test for differences in kelp forest structure between Regions (fixed factor) and Sites (random factor nested within Region). Permutations (4999) were conducted under a reduced model and were based on Bray-Curtis similarity matrices constructed from $4^{\text {th }}$ root-transformed abundance/cover data. Kelp forest structure was quantified through quadrat-scale abundance measures, quadrat-scale cover estimates and transect-scale canopy cover estimates. Significant values (at $\mathrm{P}<0.05$ ) are indicated in bold.

\begin{tabular}{lllllllllll} 
& \multicolumn{3}{l}{ Region } & \multicolumn{4}{c}{ Site } & \multicolumn{3}{c}{ Residual } \\
& $d f$ & MS & F & P & $d f$ & MS & F & P & MS \\
Quadrat-scale abundance & 3 & 2773 & 2.03 & $\mathbf{0 . 0 4 7}$ & 8 & 1361 & 7.38 & $\mathbf{0 . 0 0 1}$ & 84 & 184 \\
Quadrat-scale percent cover & 3 & 2486 & 2.38 & $\mathbf{0 . 0 1 0}$ & 8 & 1043 & 5.98 & $\mathbf{0 . 0 0 1}$ & 84 & 174 \\
Transect-scale canopy cover & 3 & 763 & 2.82 & $\mathbf{0 . 0 0 8}$ & 8 & 763 & 14.46 & $\mathbf{0 . 0 0 1}$ & 36 & 52.7
\end{tabular}


Table 3. Results of univariate permutational ANOVAs to test for differences in kelp species abundance/cover between Regions (fixed factor) and Sites (random factor nested within Region). Permutations (4999) were conducted under a reduced model and were based on matrices derived from Euclidean distances between untransformed data. Kelp species were quantified by quadrat-scale abundance measures, quadrat-scale cover estimates and transect-scale canopy cover estimates. Significant values (at $\mathrm{P}<0.05)$ are indicated in bold.

\begin{tabular}{|c|c|c|c|c|}
\hline Region & & Site & & Residual \\
\hline$d f \quad \mathrm{MS}$ & $\mathrm{F}$ & MS & $\mathrm{F}$ & $d f \quad \mathrm{MS}$ \\
\hline
\end{tabular}

\section{Laminaria hyperborea}

Quadrat-scale abundance

Quadrat-scale percent cover

Transect-scale canopy cover

$\begin{array}{lllll}3 & 2413 & 1.25 & 0.296 \\ 3 & & 11476 & 1.63 & 0.231 \\ 3 & 165 & 0.31 & 0.775\end{array}$

$\begin{array}{lll}1918 & 27.8 & \mathbf{0 . 0 0 1}\end{array}$

$84 \quad 68.7$

$\begin{array}{llll}8 & 7033 & 22.7 & \mathbf{0 . 0 0 1}\end{array}$

$84 \quad 309$

8

$533 \quad 5.48$

0.002

$36 \quad 97.3$

\section{Laminaria ochroleuca}

Quadrat-scale abundance

Quadrat-scale percent cover

Transect-scale canopy cover

Saccharina latissima

Quadrat-scale abundance

Quadrat-scale percent cover

3

$\begin{array}{lll}2.89 & 1.42 & 0.314\end{array}$

$\begin{array}{lll}67.9 & 0.74 & 0.538\end{array}$

$\begin{array}{llll}8 & 2.04 & 1.94 & \mathbf{0 . 0 4 1} \\ 8 & 91.7 & 2.11 & \mathbf{0 . 0 3 8}\end{array}$

$\begin{array}{ll}84 & 1.04 \\ 84 & 43.3\end{array}$




\begin{tabular}{|c|c|c|c|c|c|c|c|c|c|c|}
\hline Transect-scale canopy cover & 3 & 8.57 & 0.92 & 0.487 & 8 & 9.29 & 4.62 & 0.003 & 36 & 2.01 \\
\hline \multicolumn{11}{|l|}{ Alaria esculenta } \\
\hline Quadrat-scale abundance & 3 & 23.6 & 3.51 & 0.005 & 8 & 6.70 & 2.52 & 0.005 & 84 & 2.65 \\
\hline Quadrat-scale percent cover & 3 & 674 & 14.7 & 0.006 & 8 & 45.8 & 0.97 & 0.469 & 84 & 47.2 \\
\hline Transect-scale canopy cover & 3 & 62.8 & 1.20 & 0.013 & 8 & 52.1 & 4.97 & 0.001 & 36 & 10.5 \\
\hline \multicolumn{11}{|l|}{ Saccorhiza polyschides } \\
\hline Quadrat-scale abundance & 3 & 0.34 & 0.64 & 0.659 & 8 & 0.53 & 1.33 & 0.186 & 84 & 0.39 \\
\hline Quadrat-scale percent cover & 3 & 15.87 & 1.01 & 0.476 & 8 & 15.6 & 1.35 & 0.219 & 84 & 11.5 \\
\hline Transect-scale canopy cover & 3 & 2.61 & 4.32 & 0.013 & 8 & 0.60 & 3.95 & 0.002 & 36 & 0.15 \\
\hline
\end{tabular}




\section{Figure legends}

Fig. 1. Map of UK indicating the 4 study regions: northern Scotland (A), western Scotland (B) southwest Wales (C) southwest England (D). Inset maps indicate locations of the 3 study sites within each region.

Fig. 2. Annual temperature variability at a subtidal study site ( $2 \mathrm{~m}$ depth b.c.d.) within each study region. Temperature record spans July 2014-July 2015, with measurements obtained every 30 minutes.

Fig. 3. Metric MDS plots depicting the structure of kelp forests at each site (labels) within each region (symbols). Ordinations are based on Bray-Curtis similarity matrices constructed from $4^{\text {th }}$-root transformed data collected at the quadrat/transect scale. Kelp forest structure was quantified through quadrat-scale abundance measures (A), quadrat-scale cover estimates (B) and transect-scale canopy cover estimates $(\mathrm{C})$.

Fig. 4. Metric MDS plots depicting the structure of kelp forests at each site (labels) within each region (symbols). Ordinations are based on Bray-Curtis similarity matrices constructed from $4^{\text {th }}$-root transformed data; centroids represent site averages. Kelp forest structure was quantified through quadrat-scale abundance measures (A), quadrat-scale cover estimates (B) and transectscale canopy cover estimates (C).

Fig. 5. Summary of SIMPER results to determine which species were the primary contributors to the observed differences in kelp forest structure between regions. Lower-left half of each grid shows most important contributor to the observed differences between regions, upper-right half shows second-most important discriminatory species. Species are colour coded: orange $=$ Laminaria hyperborea $(\mathrm{LH})$, yellow $=$ L. ochroleuca $(\mathrm{LO})$, green $=$ Saccharina latissima, blue $=$ Alaria esculenta $(\mathrm{AE})$, pink $=$ Saccorhiza polyschides $(\mathrm{SP})$. The percentage contribution of each kelp species to the total observed dissimilarity between regions is also shown. Kelp forest structure was quantified through quadrat-scale abundance measures (A), quadrat-scale cover estimates (B) and transect-scale canopy cover estimates (C).

Fig. 6. Mean $\left( \pm\right.$ SE) abundance (inds $\left.m^{-2}\right)$ and cover $(\%)$ of each kelp species at survey sites within each region. Kelp forest structure was quantified through quadrat-scale abundance measures (left column), quadrat-scale cover estimates (centre column) and transect-scale canopy cover estimates (right column). 


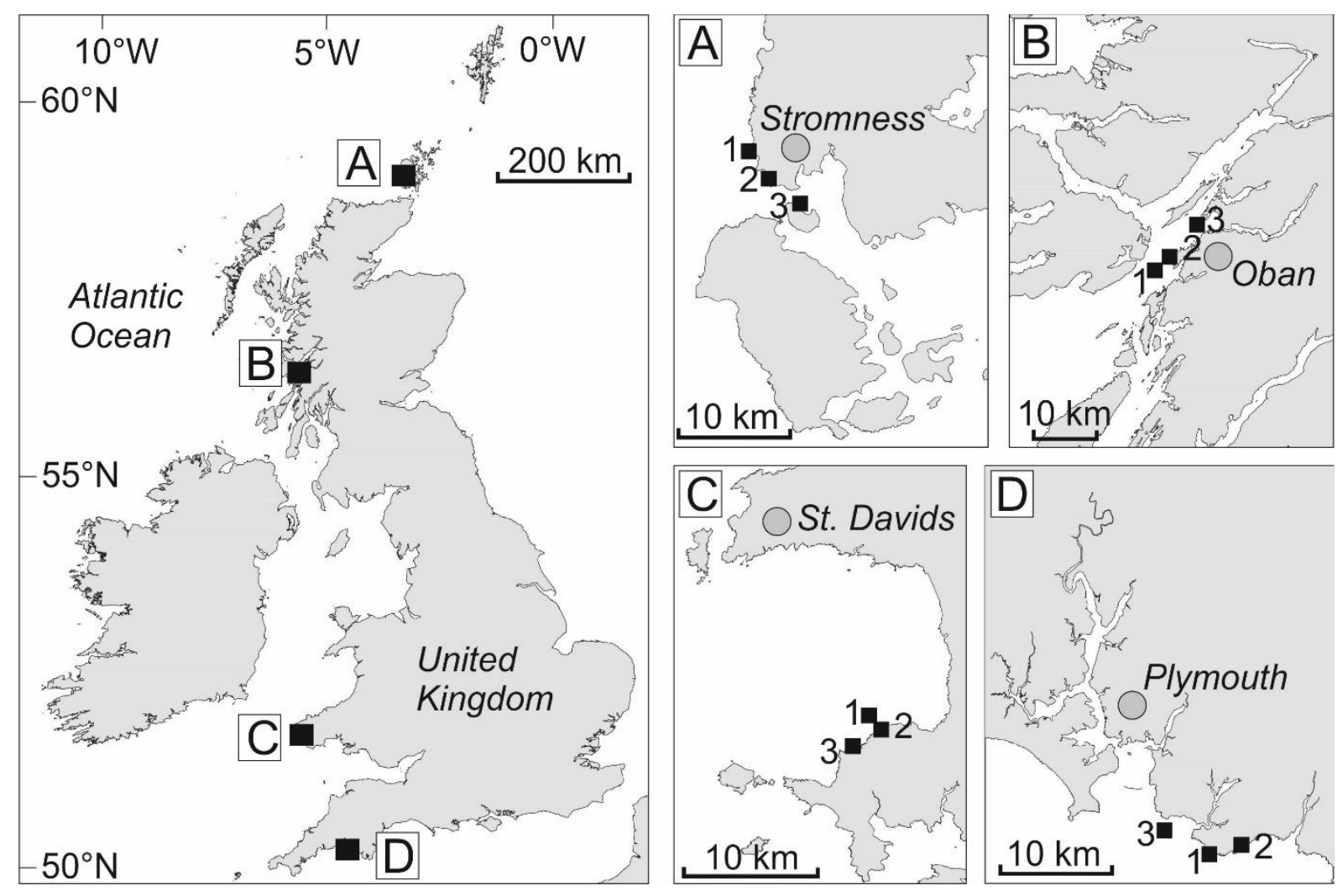

Fig. 1 




Fig. 2 

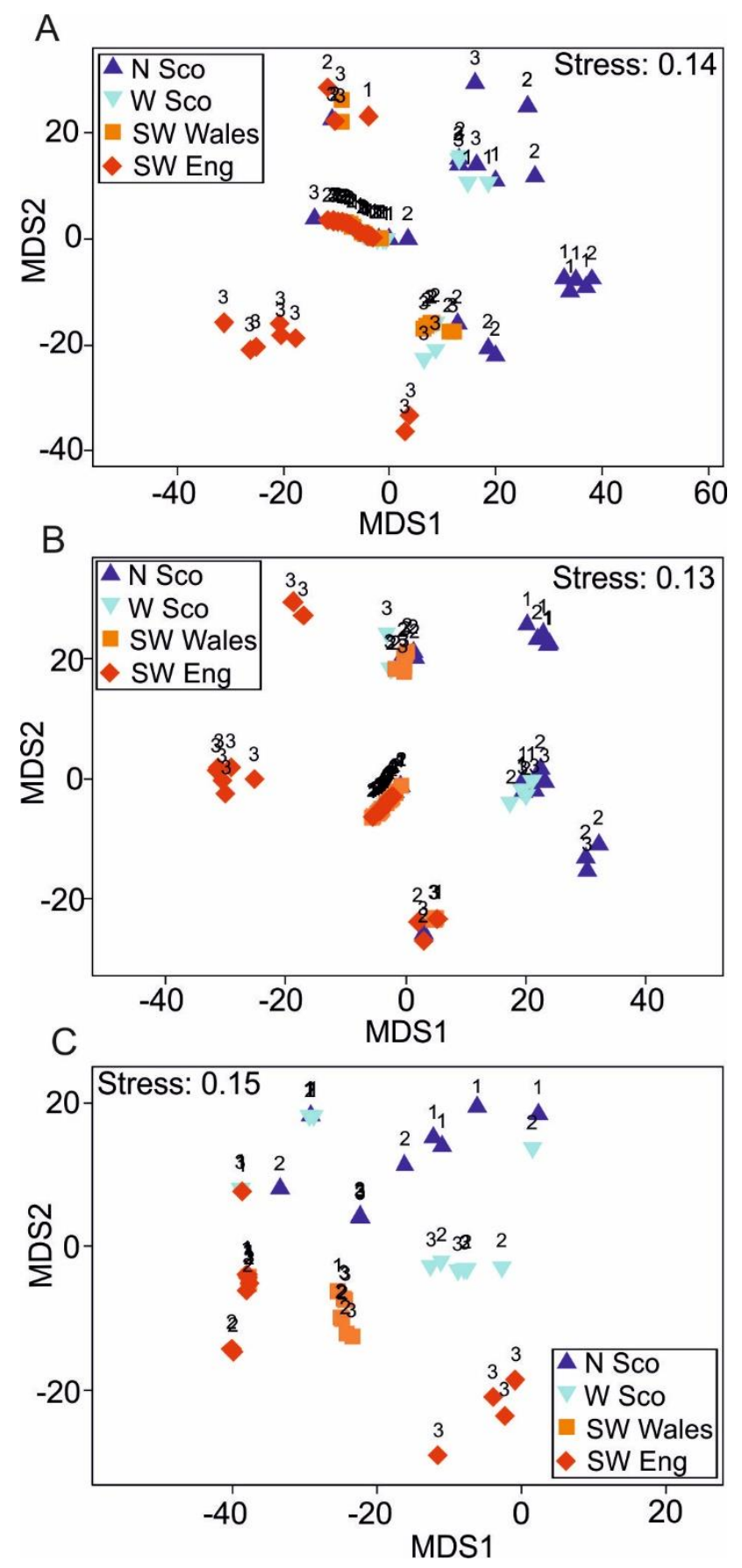

Fig. 3 

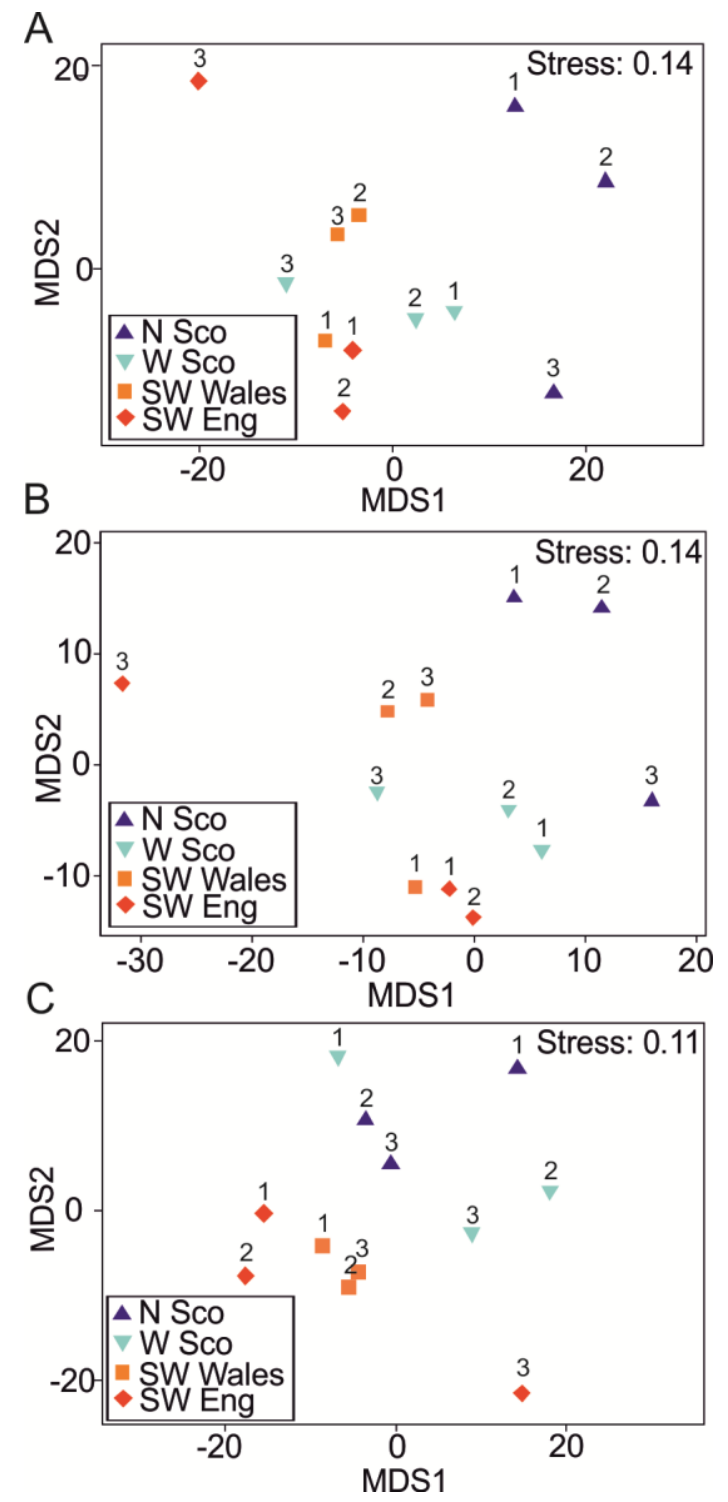

Fig. 4 
A

\begin{tabular}{|c|c|c|c|c|c|}
\hline Region & N Scotland & W Scotland & sW Wales & SW England & \\
\hline N Scotland & & $27 \%$ & $26 \%$ & $20 \%$ & \\
\hline W Scotland & $39 \%$ & & $26 \%$ & $19 \%$ & \\
\hline SW Wales & $36 \%$ & $41 \%$ & & $27 \%$ & क⿺ \\
\hline SW England & $29 \%$ & $36 \%$ & $37 \%$ & & . \\
\hline
\end{tabular}

B

\begin{tabular}{|c|c|c|c|c|c|}
\hline Region & N Scotland & W Scotland & sW Wales & SW England & \\
\hline N Scotland & & $30 \%$ & $31 \%$ & $23 \%$ & \\
\hline W Scotland & $45 \%$ & & $23 \%$ & $19 \%$ & \\
\hline SW Wales & $42 \%$ & $47 \%$ & & $28 \%$ & \\
\hline SW England & $32 \%$ & $43 \%$ & $41 \%$ & & \\
\hline
\end{tabular}

1st most important contributor to observed difference

C

\begin{tabular}{|c|c|c|c|c|c|}
\hline Region & N Scotland & W Scotland & sW Wales & SW England & \\
\hline N Scotland & & $31 \%$ & $24 \%$ & $23 \%$ & \\
\hline W Scotland & $41 \%$ & & $32 \%$ & $28 \%$ & \\
\hline sW Wales & $51 \%$ & $46 \%$ & & $31 \%$ & \\
\hline SW England & $37 \%$ & $29 \%$ & $40 \%$ & & $\frac{\xi}{0}$ \\
\hline
\end{tabular}

1st most important contributor to observed difference

Fig. 5 

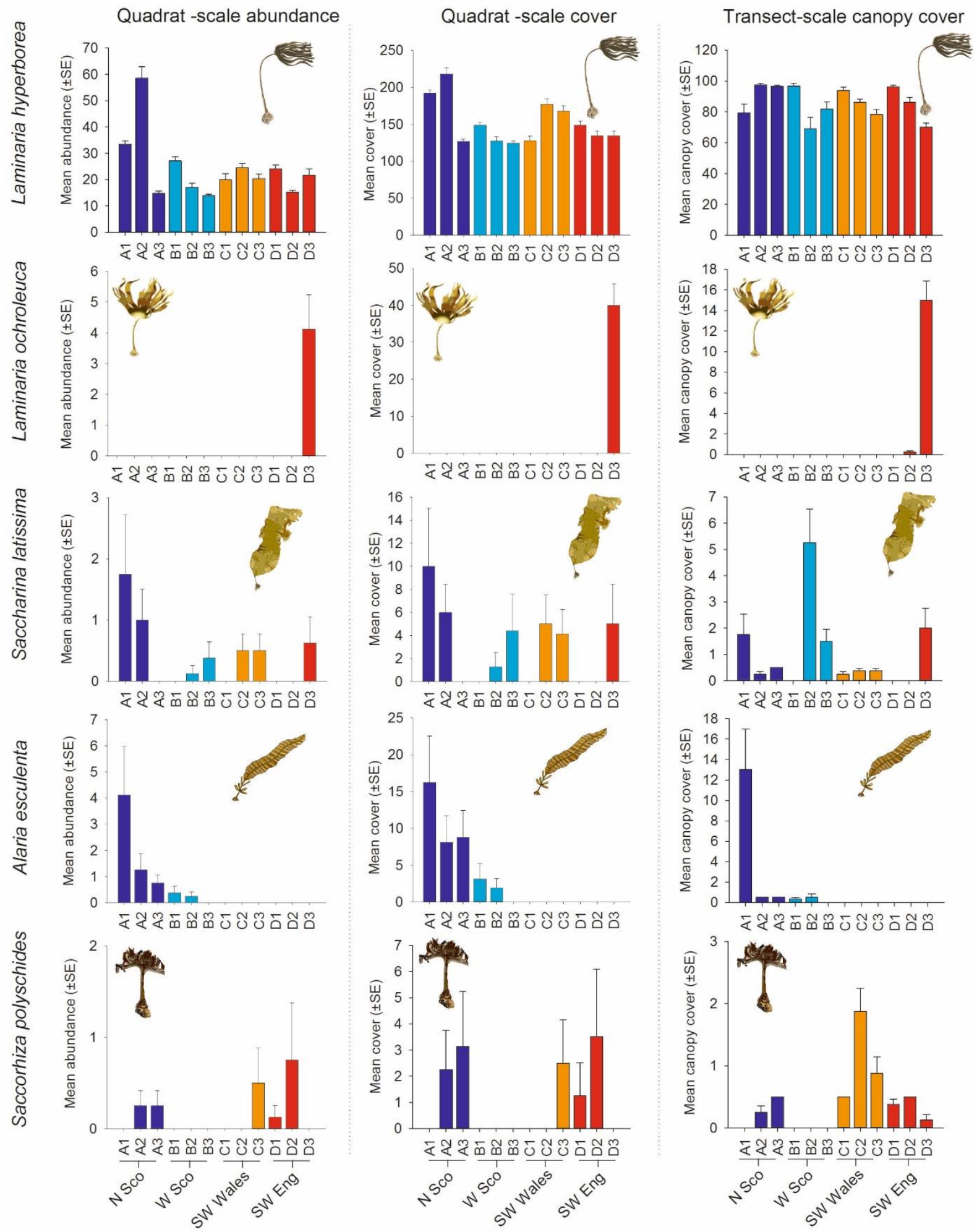

Fig. 6 